\title{
Healthy Parent Carers: feasibility randomised controlled trial of a peer-led group-based health promotion intervention for parent carers of disabled children
}

Gretchen Bjornstad ${ }^{1,2^{*}}$ (D), Beth Cuffe-Fuller ${ }^{1}$, Obioha C. Ukoumunne ${ }^{2}$, Mary Fredlund ${ }^{1,2}$, Annabel McDonald ${ }^{1}$, Kath Wilkinson ${ }^{1}$, Jenny Lloyd ${ }^{2,3}$, Annie Hawton ${ }^{2,4}$, Vashti Berry², Mark Tarrant ${ }^{2}$, Aleksandra Borek ${ }^{5}$, Katharine Fitzpatrick ${ }^{1}$, Annette Gillett ${ }^{1}$, Shelley Rhodes ${ }^{6}$, Stuart Logan ${ }^{1,2}$ and Christopher Morris ${ }^{1,2}$

\begin{abstract}
Background: Parent carers of children with special educational needs or disability are at higher risk of poor mental and physical health. The need for a tailored, peer-led group programme was raised by parent carers, who codeveloped the Healthy Parent Carers programme with researchers. This study aimed to test the feasibility of programme delivery in community settings, and the feasibility and acceptability of a randomised controlled trial design.

Methods: Participants were individually randomised with concealed allocation to a structured group programme and access to online resources (intervention), or access to the online resources only (control). Measures of wellbeing and secondary and economic outcomes were collected before randomisation, immediately postintervention, and 6 months post-intervention. Descriptive statistics on recruitment and attrition, demographics, attendance, and fidelity of intervention delivery were analysed with feedback on the acceptability of the trial design.

Results: One hundred and ninety-three parent carers expressed an interest in taking part. Ninety-two participants recruited from across six sites were randomised (47 intervention, 45 control). Lead and assistant facilitators were trained and delivered the group sessions. Sixteen (34\%) participants in the intervention arm did not attend any sessions, and attendance varied across sites and sessions. One participant withdrew post-randomisation, and 83 (90\%) participants completed outcome measures at the six-month follow-up.
\end{abstract}

\footnotetext{
* Correspondence: g.j.bjornstad@exeter.ac.uk

'Peninsula Childhood Disability Research Unit (PenCRU), University of Exeter

Medical School, University of Exeter, St. Luke's Campus, Heavitree Road,

Exeter EX1 2LU, UK

${ }^{2}$ NIHR Applied Research Collaboration South West Peninsula (PenARC),

University of Exeter Medical School, University of Exeter, St. Luke's Campus,

Heavitree Road, Exeter EX1 2LU, UK

Full list of author information is available at the end of the article
}

C C The Author(s). 2021 Open Access This article is licensed under a Creative Commons Attribution 4.0 International License, which permits use, sharing, adaptation, distribution and reproduction in any medium or format, as long as you give appropriate credit to the original author(s) and the source, provide a link to the Creative Commons licence, and indicate if changes were made. The images or other third party material in this article are included in the article's Creative Commons licence, unless indicated otherwise in a credit line to the material. If material is not included in the article's Creative Commons licence and your intended use is not permitted by statutory regulation or exceeds the permitted use, you will need to obtain permission directly from the copyright holder. To view a copy of this licence, visit http://creativecommons.org/licenses/by/4.0/ The Creative Commons Public Domain Dedication waiver (http://creativecommons.org/publicdomain/zero/1.0/) applies to the data made available in this article, unless otherwise stated in a credit line to the data. 
Conclusions: The study demonstrated that it was feasible to deliver the programme in community settings. The number of parent carers who expressed interest signifies the need for such a programme and the feasibility of recruiting to a definitive trial. Loss to follow-up was low. Further research is needed to explore ways to reduce barriers to participation in person and assess the feasibility and acceptability of programme content and delivery for more ethnically diverse groups, and potentially using interpreters. Given the Covid-19 pandemic and delivery format feedback, there is also a need to investigate remote or blended delivery strategies. Although the results indicate that a definitive trial is feasible, programme impact would be strengthened through exploration of these uncertainties.

Trial registration: ISRCTN, ISRCTN15144652, registered on 25 October 2018, ClinicalTrials.gov, NCT03705221, registered on 15 October 2018.

\section{Key messages regarding feasibility}

- What uncertainties existed regarding the feasibility?

The Healthy Parent Carers programme was developed using intervention mapping and was initially tested with one group of seven parent carers. Following this, the intervention content and delivery methods were refined based on feedback from programme facilitators and participants.

Further testing was needed to investigate whether it can be feasibly delivered in community settings by trained facilitators who had not been involved in the development of the programme.

Testing the design for a randomised controlled trial to determine whether a definitive trial is likely to be acceptable to participants and feasible to evaluate the effectiveness and cost-effectiveness of the programme.

- What are the key feasibility findings?

Six venues in a variety of community settings were established for group delivery by trained facilitators.

A sufficient number of participants were recruited in each study site and randomised to groups in the intervention arm (total $\mathrm{N}=92$ ).

According to facilitators' self-reports, $90 \%$ of programme activities were delivered across all groups.

Participant attendance was variable, with two groups having consistently low numbers attending, whereas others had higher levels of attendance.

Outcome data were collected from $91 \%$ of participants at post-intervention follow-up and $90 \%$ of participants at 6-month follow-up.

Most participants found the trial design to be acceptable, although some would have preferred to choose the mode of programme delivery.

The outcome measures were largely acceptable to participants, although some technical problems with the electronic patient-reported outcomes system were reported.

The cost-effectiveness framework was found to be feasible for implementation in a trial.

- What are the implications of the feasibility findings for the design of the main study?

There was considerable interest in the study from parent carers, indicating that the recruitment strategy could be effective for recruiting sufficient numbers to trial sites.

Social media and events were found to be the most helpful elements of the recruitment strategy.

The trial design was generally acceptable to parent carers. Clearer information about allocation in adverts may help to manage expectations. The electronic patient-reported outcomes system should be revisited and re-tested by users before implementation in a definitive trial.

Retention and participant response to followup was successful utilising a combination of automated email reminders, phone calls, text messages and vouchers for acknowledgements. This system should be replicated in a definitive trial to ensure similar follow-up rates.

\section{Background}

As of January 2019, there were an estimated 1,320,000 school-aged children in England with special educational needs, which is $14.9 \%$ of all pupils [1]. Around 1.1 million children $(8 \%)$ in the UK have a disability, according to the Family Resources Survey 2018/2019 [2]. Parent carers of children with special educational needs or disability (SEND) provide care throughout their childhood, through their transition to adult services, and sometimes beyond. Over the past several years, many international studies have consistently shown that this long-term caring role puts parent carers at greater risk of mental health problems, particularly stress and depression, and physical health problems, compared with other parents [3-17]. These problems may worsen over time and affect 
parent carers' ability to care for their children [18]. However, parent carers' experiences vary and are not necessarily related to the complexity of their child's disability $[5,6]$, with some reporting positive impacts $[9,19]$.

The need for an intervention specifically designed to address this risk was raised by parent carer members of the Peninsula Childhood Disability Research Unit (PenCRU) Family Faculty public involvement group. These parent carers worked closely with researchers over several years to co-create the Healthy Parent Carers (HPC) as a peer-led, group-based programme. The programme was developed iteratively and systematically using the Intervention Mapping approach [20]. A proof-ofprinciple study with one group of seven parent carers indicated that the intervention was feasible to deliver in a university setting by facilitators involved in its development [21]. It was also found to be acceptable to and valued by parent carers. The facilitator's intervention delivery manual and programme content were revised following feedback.

Before progressing to a definitive randomised controlled trial, it was essential to assess the feasibility of delivery of the programme by newly trained facilitators outside of the intervention development team in a range of community settings in several groups at one time and to assess the feasibility and acceptability of trial processes [22].

\section{Methods}

\section{Aims}

This trial aimed to evaluate whether the programme can be delivered in the community by newly trained facilitators and whether a randomised controlled trial design with cost-effectiveness analysis is feasible and acceptable to participants.

This paper focuses on the assessment of the following objectives:

- Feasibility of establishing venues and recruiting and training facilitators to deliver the intervention

- Feasibility of recruiting participants in different sites

- Acceptability of trial processes to parent carers

- Fidelity of intervention delivery in terms of format, content, and quality

- Attendance in the group programme

- Loss to follow-up and estimates of standard deviations for the outcomes to help inform the sample size calculation for the definitive trial

- Feasibility of the proposed cost-effectiveness framework for a future definitive trial

The acceptability of the intervention and training for facilitators was also assessed, but results are reported separately in order to present adequate details (Lloyd J,
Bjornstad G, Borek A, Cuffe-Fuller B, Fredlund M, McDonald A, Tarrant M, Berry V, Wilkinson K, Mitchell $S$, et al: The Healthy Parent Carers programme: mixedmethods process evaluation and refinement of a health promotion intervention, Under review).

Criteria for progression to a definitive trial were set a priori and were as follows:

a) Recruit a minimum of 48 participants, which was the minimum number to enable all six sites to be randomised and the intervention to be tested.

b) Six intervention groups delivered in the intervention arm, assessed by establishing 6 venues, and identifying and training facilitators, and groups completing the programme curriculum.

c) At least $80 \%$ of participants completing measures at 6-month follow-up or a clear plan to achieve this in the trial.

\section{Study design}

A feasibility study using a parallel group randomised controlled trial design and within-trial cost-effectiveness analysis was carried out in six sites in the South West of England. Participants were randomly allocated to receive the group-based HPC programme and access to online programme resources (intervention arm) or to receive access to the online resources only (control arm). Participant feedback forms, participant interviews, facilitator questionnaires and feedback forms, facilitator checklists, and a facilitator focus group provided data for the process evaluation. Outcome data collection took place at three time points in both trial arms: at baseline (prior to randomisation), immediately post-intervention, and 6 months later. The trial design and the flow of participants through the trial are illustrated in the CONSORT Extension to Pilot and Feasibility Trials flow diagram (Fig. 1). The CONSORT reporting checklist is provided as an additional file (see Additional file 1). The methods were provided in detail in the protocol [23].

\section{Public involvement}

This project has involved parent carers and stakeholders from inception to ensure that (a) the research is conducted in an acceptable manner, (b) the research outputs are relevant and useful to parents of children with special educational needs and disabilities, and (c) our dissemination materials and methods are appropriate and accessible.

Over 40 parent carers from the PenCRU Family Faculty public involvement group have been involved in all stages of developing the HPC programme and designing and conducting the feasibility trial. During this trial, parent carers met with the research team for a half-day meeting at least once per school term. They were also involved in additional ways, such as volunteering to 


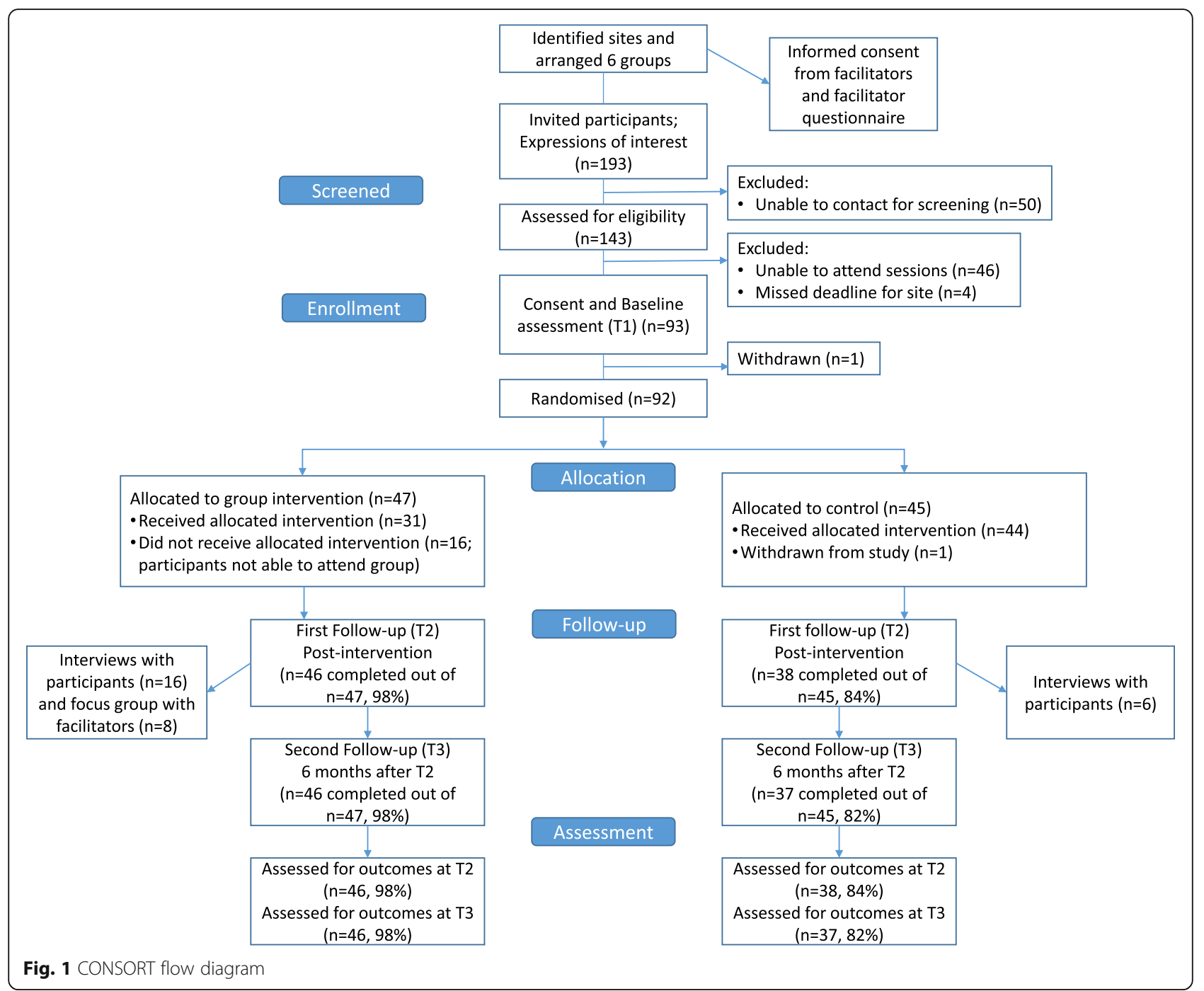

review and provide feedback on the online programme resources, the recruitment advertisements and participant information sheets, and the outcome measures used in this study. They continued to meet to interpret the results, disseminate findings, and plan subsequent stages of the research. Two parent carers were co-investigators of this trial, delivered the training, and are co-authors of this paper (MF and AM).

Our Stakeholder Advisory Group (SAG) included 20 representatives from the Local Authority, Public Health, four parent carer forums in south west England, relevant charities, and special schools. This group met four times over the course of the study to provide input on the design of the study, the establishment of programme delivery sites, and facilitator and participant recruitment.

\section{Establishing sites}

Six venues were established in the south west of England. These varied in nature to assess the suitability of programme delivery in a variety of settings. They comprised two special schools, one children's hospice, one community adult learning centre, one parent carer forum office, and one community hotel that regularly provides a venue for local parent carer groups and other community events. All venues met requirements for delivery of the group sessions in terms of accessibility (both within the building and in terms of parking and/or public transport), room size, availability of Wi-Fi and a projector and screen, toilets, facilities to make tea and coffee, and cost. Days, times, durations, and frequencies of sessions were agreed with each venue. The six venues also varied in terms of location (north or south Devon, Cornwall, and Somerset) and geography (cities or towns).

\section{Recruitment and training of facilitators}

Lead Facilitators were recruited by referral via the Council for Disabled Children (CDC). The CDC runs a 
training programme for parent carers called the 'Expert Parent Programme', which is delivered by parent carers. Three of these parent carers were selected as being among the most experienced at delivering group interventions to parent carers and being available to deliver groups in the south west of England.

Assistant Facilitators were recruited through adverts shared by members of the SAG to contacts in the six delivery areas in July-September 2018. Adverts included information about the role and a person specification which included criteria such as being a parent carer, having current knowledge and understanding of how being a parent carer can impact on health and wellbeing, the ability to work with parents in a sensitive and empathic way, upholding confidentiality at all times, being non-judgemental, and being available to attend scheduled train-the-facilitator sessions and weekly group sessions. They were not expected to have experience delivering interventions. Applicants were interviewed by a researcher by telephone and selection decisions were made by the research team based on applications and interview notes. The aim was for the Assistant Facilitators to be local to the group site; however, this was not always possible with distances from the facilitator/s' home to the venue ranging from 12 to 40 miles.

All Lead and Assistant Facilitators provided written informed consent before beginning training. Facilitator training was led by two parent carers who co-developed the programme and facilitated the group in the previous study (MF and AM), supported by researchers [21]. The training was structured and documented in a training manual. Three Lead Facilitators received the first 2 days of training. After this initial training, it became clear that one of these facilitators would be unable to deliver group sessions due to travel logistics. Two Lead Facilitators attended the subsequent 2 days of training along with six Assistant Facilitators and three reserve Assistant Facilitators. A further day of training for all facilitators was provided as a refresher after the first two groups completed all sessions and before the next four groups started sessions.

\section{Participant recruitment}

Recruitment took place in two sites in one school term (October-December 2018) and in four further sites in the subsequent two terms (January-May 2019). Press releases and local television and radio interviews/online features in newspapers were used to announce the study. Members of the SAG shared the study advert with their contacts and networks. The advert and information about the study was also shared on our social media sites, with special schools and Special Educational Needs Coordinators (SENCOs) in mainstream schools, Information and Advice Services, advisory teaching services, disabled children's services, and other contacts such as parent carer groups in the south west of England. Members of the research team also attended events hosted by parent carer forums and groups, where they shared information about the study, with opportunities for parents to discuss the study with staff individually if they wished.

Screening was conducted by telephone or in person at recruitment events by research staff. Inclusion criteria were (1) primary carers of children with additional needs or disability (participants who self-identify as primary carers were eligible; the child could be up to 25 years old consistent with the current Department of Health and Department of Education Special Educational Needs and Disability (SEND) legislation in England and The Children's Act; no named diagnosis was necessary, and we did not limit to specific conditions), (2) willing and able to attend the programme group meeting session(s) on arranged dates/times, and (3) able to access online information. Only one parent per household were able to take part as individuals were randomised. Written informed consent was provided in person in individual meetings with research staff.

We aimed to recruit 96 participants (16 per site on average). This is large enough to estimate the standard deviation for continuous outcomes in each arm within $29 \%$ of its true value based on the upper bound of the $95 \%$ confidence interval, if $80 \%$ of the sample provide data at follow-up. A minimum of eight participants per site needed to be recruited to ensure that at least four participants would be allocated to each of the six HPC programme delivery groups within the intervention arm.

\section{Participant allocation}

A computer-generated randomisation sequence was used to allocate participants on a 1:1 ratio to intervention and control conditions. A block randomisation scheme was implemented to ensure equal numbers of participants were allocated to each trial arm, stratified by group delivery site. The allocation sequence was concealed from researchers using a randomisation service set up and maintained by the Exeter Clinical Trials Unit. Blinding was not used in this trial.

Participants allocated to the intervention arm were sent details of the group sessions and contacted by phone by the Lead Facilitator of their group. Participants in both the intervention and control arms received a link to the online programme resources and instructions on the webpage.

\section{Intervention}

The intervention arm involved the peer-led, HPC programme delivered in groups, as well as access to online resources. Full details of the intervention, including 
its development, logic model, and content (e.g. activities, behaviour change techniques), are available [21]. The programme aims to foster a sense of shared social identity as members of the programme group, enable social support from fellow group members, and promote parent carers' confidence, motivation, and empowerment to take steps to improve their health and wellbeing (i.e. engage in health-promoting activities). These components may cultivate the conditions for change necessary for individuals to feel able to make their own plan to prioritise healthy behaviours in ways that are feasible and important to them [24].

The programme content is based around a set of universal and evidence-based actions (called CLANGERS) associated with health and wellbeing. CLANGERS stands for Connect, Learn, be Active, Notice, Give, Eat well, Relax, and Sleep [25]. The 'CLANG' component comprises the 'Five Ways to Wellbeing' based on the evidence from the Foresight project on Mental Capital and Wellbeing [26]. Each of these behaviours is potentially more difficult for parent carers.

The programme consists of 12 modules. The modules can be delivered in groups over 6 weekly sessions (comprising two modules per session lasting four hours) or 12 weekly sessions (one module per session lasting $2 \mathrm{~h}$ ). In this study, the 6-session model was delivered in 5 sites in the daytime, and the 12-session model was delivered in one site in the evenings.

The online resources are organised into the same 12 modules, each with a text document to read (approximately 3 pages) and one or more video or audio files with content illustrating the module topic and providing information. Participants in the intervention arm received a link and password to the site for their group, and the materials were added on a weekly basis in line with their group's progress through the modules.

Each HPC group was delivered by one Lead Facilitator and one Assistant Facilitator. One Lead Facilitator delivered two groups and the other delivered four groups. Each group had a different Assistant Facilitator.

\section{Comparison}

Participants in the comparison arm were given access to the online resources for the programme only. These were provided on a password-protected website with the resources for all modules available at once, to progress at their own pace.

\section{Outcome measures}

All participants were asked to complete measures at three time points in both trial arms: at baseline (prior to randomisation), immediately post-intervention for their group (dates ranged from April-July 2019, and 6 months later (September 2019-January 2020). Measures were completed using an online platform maintained by the Exeter Clinical Trials Unit. Wellbeing was measured using the Warwick-Edinburgh Mental Wellbeing Scale (WEMWBS) [27]. Mental health was assessed using the Patient Health Questionnaire-9 (PHQ-9) [28-30]. If a participant scored higher than 0 on question 9 on the PHQ-9 ('Thoughts that you would be better off dead or of hurting yourself in some way'), this was recorded, and a member of the research team followed the study safeguarding protocol.

The Health Promoting Activities Scale (HPAS) was used to measure the frequency of participation in activities to promote health $[31,32]$. The Patient Activation Measure (PAM) was used to measure participants' skills, knowledge, and confidence in managing their own health [33, 34]. Protective factors such as resilience, social connections, and practical support were measured using the Parents' Assessment of Protective Factors (PAPF) [35].

The EuroQol 5 Dimensions (EQ-5D-5L) was used to measure health-related quality of life [36]. The ICEpop CAPability measure for Adults (ICECAP-A) was used to measure the following aspects of wellbeing: attachment, stability, achievement, enjoyment, and autonomy [3739]. Participants' use of health care, social care, and wider societal resources was measured using a studyspecific resource use questionnaire. Full details of the measures used are in the study protocol [23].

Participants received a $£ 25$ shopping voucher for completing measures at each time point. Participants were contacted to complete post-intervention and follow-up measures by automated email reminders, with phone calls and text messages from researchers if required.

\section{Cost-effectiveness framework}

As part of the feasibility study, a framework was developed and tested for assessing the cost-effectiveness of the intervention in a future randomised trial. This included:

a) Establishing methods for estimating intervention resource use and costs (e.g. training of facilitators, facilitators' time, venue hire), in collaboration with the programme facilitators and site representatives;

b) Developing a health, social and wider care service resource use questionnaire in collaboration with parent carers, drawing on measures in the Database of Instruments for Resource Use Management (DIRUM) repository [40];

c) Assessing the feasibility of the EQ-5D-5L [41] and the ICECAP-A [42] for use with parent carers, for use in estimating quality-adjusted life-years (QALYs) and wellbeing-adjusted life-years (WALYs).

\section{Process evaluation data}

A process evaluation ran alongside this trial to understand delivery issues and experiences of delivering or 
participating in the programme. Qualitative and quantitative data were collected to address the process evaluation questions addressed in this paper as described below. Further process evaluation questions, methods, and results are reported separately (Lloyd J, Bjornstad G, Borek A, Cuffe-Fuller B, Fredlund M, McDonald A, Tarrant M, Berry V, Wilkinson K, Mitchell S, et al: The Healthy Parent Carers programme: mixed-methods process evaluation and refinement of a health promotion intervention, Under review).

\section{Recruitment and screening data}

During recruitment and screening, data were collected by the research team to identify how participants heard about the study to assess the marketing strategy. Some parent carers who opted not to take part provided the reasons for their decision, and these reasons were coded without any personal details.

\section{Facilitator delivery checklists and session recordings}

Self-report checklists, completed jointly by Lead and Assistant Facilitators after each session, were used to record the content that had been covered (adherence), the duration of sessions (dose), how well the facilitator felt the session went, and the participants' engagement. Facilitators also recorded participants' attendance at each session, including reasons for non-attendance where provided by participants.

Group sessions were audio-recorded and nine modules were randomly sampled to assess fidelity of content delivery, using the same checklist as used by facilitators. The nine module recordings were assessed using the checklist by one researcher (BCF) and independently double-scored by a second researcher (AB). Checklist scores were compared between both researchers, and between the researchers and the facilitators to assess the proportion of agreement in identifying delivered content.

\section{Participant feedback forms and interviews}

Feedback forms were completed by participants in both arms about the programme content, delivery, their experiences, and any contamination between trial arms.

Twelve participants in the intervention arm who attended group sessions (two from each site) and six participants from the control arm (one from each site) were interviewed about their experience and perceived impact of the programme, and about acceptability of trial processes. Four participants in the intervention arm who did not attend any group sessions were interviewed to ask about barriers to attendance.

\section{Qualitative analyses}

Transcribed participant interviews and free-text data from participant questionnaires (feedback forms) were uploaded to NVivo (version 12). A coding framework was developed by three researchers (BCF, $\mathrm{AB}$, and $\mathrm{JL}$ ) to categorise and analyse the data. Interview transcripts (n $=18$ ) were coded by BCF, with $9(41 \%)$ double-coded by $\mathrm{AB}$ and JL. Interviews with non-attenders $(n=4)$ were summarised. Qualitative data from screening and attendance records were recorded in Excel spreadsheets and coded by BCF and checked by GB, with final codes agreed by both.

\section{Quantitative analyses}

Descriptive statistics were used to summarise recruitment and retention of participants, demographics, attendance, and fidelity of intervention delivery, as well as participants' feedback on the acceptability of the trial design.

Outcomes were compared between the trial arms at the post-intervention and follow-up data collection points according to the arm that participants were randomised to in keeping with the intention-to-treat principle. Random effects ("multilevel") linear regression models were fitted to compare continuous outcomes, allowing for clustering within groups in the intervention arm of the trial. Satterthwaite's degrees of freedom correction was used [43], given the small number of groups (clusters). Unadjusted analyses and analyses adjusted for study site were carried out. Missing data were not imputed. These analyses were exploratory, and $p$ values are not reported in line with the extension to the CONSORT statement for reporting randomised pilot and feasibility studies [44]. We report estimates of correlations between baseline and follow-up for the outcome measures as well as estimates of standard deviations for the outcomes, with 95\% confidence intervals.

\section{Results \\ Feasibility of trial design Participants}

One hundred and ninety-three parent carers enquired about taking part in the study. Of those, $143(74.1 \%$ (95\% confidence interval: 67.3 to $80.1 \%)$ ) were formally assessed for eligibility, with the remaining 50 not responding for further contact after initial enquiries. Of those who enquired about the study, 141 indicated how they heard about the study (Table 1).

Ninety-two participants ( $47.7 \%$ of those who expressed an interest (95\% confidence interval: $40.4 \%$ to $55.0 \%)$ ) provided written informed consent in person with a researcher before completing measures and were randomised (intervention $n=47$, control $n=45$ ). A minimum of 8 participants was required for each site in order to 
Table 1 Frequency of recruitment sources

\begin{tabular}{ll}
\hline Source of study information & Number (\%) \\
\hline Social media & $41(21.2)$ \\
Event attended/held by study team & $25(13.0)$ \\
School letter or school staff contact & $16(8.3)$ \\
Parent Carer group & $16(8.3)$ \\
Friend/word of mouth & $11(5.7)$ \\
News story & $11(5.7)$ \\
Study advert shared by an organisation & $8(4.1)$ \\
PenCRU Family Faculty & $5(2.6)$ \\
Facilitator advert & $3(1.6)$ \\
Poster/flyer & $3(1.6)$ \\
Children's services & $1(0.5)$ \\
Other email & $1(0.5)$ \\
No information provided & $52(26.9)$ \\
Total & 193 \\
\hline
\end{tabular}

ensure that at least four parent carers would be allocated to attend group sessions, but the target was to recruit 16 per site. The numbers recruited varied by site with two sites recruiting under target (Torquay $n=13$; Minehead $n=12$ ) and one site recruiting over target (Plymouth $n$ $=20$ ). Recruitment improved over time, meeting our target in the last three sites. Of the two sites that were under target, one was offering evening sessions (the $12 \times$ 2-h session format) and the other was in a geographically remote coastal town. Fifty parent carers opted not to take part in the study; the reasons that they gave are presented in Table 2. One participant in the Plymouth site withdrew from the study after providing written consent, but before randomisation. One participant in the control arm (Torquay site) withdrew from the study after allocation.

Participants were aged 42.5 (8.0) years (mean (SD)), 96\% female and $97 \%$ white. Sixty-three percent of participants were married, $45 \%$ were employed either part-time or fulltime, and $16 \%$ lived in postcodes ranked in the most

Table 2 Reasons for not consenting to take part

\begin{tabular}{ll}
\hline Reason & Number (\%) \\
\hline Distance/travel to group delivery site & $18(36.0)$ \\
Childcare & $10(20.0)$ \\
Time of group sessions not suitable & $8(16.0)$ \\
Work & $7(14.0)$ \\
Missed recruitment deadline & $4(8.0)$ \\
Parent health & $1(2.0)$ \\
Babe in arms & $1(2.0)$ \\
Pregnant & $1(2.0)$ \\
Total & 50 \\
\hline
\end{tabular}

deprived quintile based on the Index of Multiple Deprivation 2019 [45]. Descriptive statistics of participants' demographic characteristics at baseline are presented in Table 3. Baseline scores on outcome measures by trial arm status are presented in Table 4. Characteristics were broadly similar between arms, with the exception of the number of participants with at least moderate depression, which was higher in the control arm $(n=30 ; 67 \%)$ than in the intervention arm $(n=18 ; 42 \%)$.

\section{Acceptability of trial processes}

Interview participants were mostly satisfied with the delivery format they were allocated to, with more positive views (from both intervention and control participants) expressed about the group programme (Table 5). Participants also discussed different circumstances and preferences for delivery formats, which could be better accounted for if participants were given a choice of joining the programme in-person or online.

Interviewees found the questionnaires (and the time to complete them) acceptable, and the questions asked relevant. Although the vast majority of interviewees had very positive views about the programme, a few were concerned about whether their positive experience was captured by the questionnaires. Three interviewees described how honestly answering the questionnaires made them concerned about triggering safeguarding processes. They also found it easy to complete the questionnaires online (especially when possible to do it on their phone), whereas found completing the initial questionnaire inperson more uncomfortable and pressured.

\section{Contamination between trial arms}

Four participants in the intervention arm (9\%) and four participants in the control arm (9\%) reported discussing the programme with participants in the other arm. No further details were collected about possible contamination.

\section{Attrition}

Outcome data were collected from 91\% (95\% confidence interval $84 \%$ to $96 \%$ ) of participants at post-intervention (98\% intervention arm; 84\% control arm) and 90\% (95\% confidence interval $82 \%$ to $95 \%$ ) of participants at 6month follow-up (98\% intervention arm; $82 \%$ control arm). However, the number of participants that provided complete data for scoring and analysis of outcomes ranged from $74(80 \%)$ to $83(90 \%)$ at post-intervention and from $71(77 \%)$ to $78(85 \%)$ at 6-month follow-up. There was no evidence that follow-up status was related to outcome scores at baseline. 
Table 3 Baseline demographics of study participants by trial arm status

\begin{tabular}{|c|c|c|c|}
\hline Characteristic & Intervention $(N=47)^{a}$ & Control $(N=45)^{b}$ & All $(N=92)^{c}$ \\
\hline \multicolumn{4}{|l|}{ Site } \\
\hline Torquay, n (\%) & $7(15)$ & $6(13)$ & $13(14)$ \\
\hline Plymouth, n (\%) & $10(21)$ & $9(20)$ & $19(21)$ \\
\hline Minehead, n (\%) & $6(13)$ & $6(13)$ & $12(13)$ \\
\hline Dawlish, n (\%) & $8(17)$ & $8(18)$ & $16(17)$ \\
\hline Bideford, n (\%) & $8(17)$ & $8(18)$ & $16(17)$ \\
\hline St Austell, n (\%) & $8(17)$ & $8(18)$ & $16(17)$ \\
\hline Female parent, n (\%) & $44(94)$ & $44(98)$ & $88(96)$ \\
\hline Age of parent, mean (SD) & $42.2(8.9)$ & $42.8(7.1)$ & $42.5(8.0)$ \\
\hline \multicolumn{4}{|l|}{ Number of children } \\
\hline One, n (\%) & $12(26)$ & $7(16)$ & $19(21)$ \\
\hline Two, n (\%) & $24(51)$ & $30(67)$ & $54(59)$ \\
\hline Three, n (\%) & $6(13)$ & $5(11)$ & $11(12)$ \\
\hline Four, n (\%) & $5(11)$ & $2(4)$ & $7(8)$ \\
\hline Five, n (\%) & $0(0)$ & $1(2)$ & $1(1)$ \\
\hline Female index child ${ }^{\mathrm{d}}, \mathrm{n}(\%)$ & $10(28)$ & $10(27)$ & $20(27)$ \\
\hline Age of index child ${ }^{d}$, mean (SD) & $11.4(5.0)$ & $11.3(5.1)$ & $11.3(5.0)$ \\
\hline \multicolumn{4}{|l|}{ Relationship status } \\
\hline Married, n (\%) & $26(55)$ & $32(71)$ & $58(63)$ \\
\hline Civil partnership, n (\%) & $2(4)$ & $0(0)$ & $2(2)$ \\
\hline Single, $n(\%)$ & $7(15)$ & $4(9)$ & $11(12)$ \\
\hline Divorced, n (\%) & $9(19)$ & $6(13)$ & $15(16)$ \\
\hline Separated, n (\%) & $2(4)$ & $3(7)$ & $5(5)$ \\
\hline Widowed, n (\%) & $1(2)$ & $0(0)$ & $1(1)$ \\
\hline \multicolumn{4}{|l|}{ Ethnicity } \\
\hline White, n (\%) & $45(96)$ & $44(98)$ & $89(97)$ \\
\hline Mixed multiple, n (\%) & $1(2)$ & $1(2)$ & $2(2)$ \\
\hline Other, n (\%) & $1(2)$ & $0(0)$ & $1(1)$ \\
\hline \multicolumn{4}{|l|}{ Employment status } \\
\hline Full-time, n (\%) & $2(4)$ & $3(7)$ & $5(6)$ \\
\hline Full-time self-employed, n (\%) & $0(0)$ & $1(2)$ & $1(1)$ \\
\hline Part-time, n (\%) & $11(24)$ & $13(30)$ & $24(27)$ \\
\hline Part-time self-employed, n (\%) & $6(13)$ & $4(9)$ & $10(11)$ \\
\hline Parent carer, n (\%) & $23(50)$ & $21(49)$ & $44(49)$ \\
\hline Unemployed, n (\%) & $4(9)$ & $0(0)$ & $4(4)$ \\
\hline Full time student, n (\%) & $0(0)$ & $1(2)$ & $1(1)$ \\
\hline \multicolumn{4}{|l|}{ Educational qualification } \\
\hline 1 to 4 GCSEs/equivalent, n (\%) & $4(9)$ & $3(7)$ & $7(8)$ \\
\hline 5+ GCSEs/equivalent, n (\%) & $8(18)$ & $5(12)$ & $13(15)$ \\
\hline 2+ A levels, n (\%) & $6(13)$ & $6(14)$ & $12(14)$ \\
\hline Degree, n (\%) & $20(44)$ & $21(49)$ & $41(47)$ \\
\hline Other, n (\%) & $7(16)$ & $8(19)$ & $15(17)$ \\
\hline
\end{tabular}


Table 3 Baseline demographics of study participants by trial arm status (Continued)

\begin{tabular}{|c|c|c|c|}
\hline Characteristic & Intervention $(N=47)^{a}$ & Control $(N=45)^{b}$ & All $(N=92)^{c}$ \\
\hline \multicolumn{4}{|l|}{ Total household income per week } \\
\hline Up to $£ 150, n(\%)$ & $4(9)$ & $0(0)$ & $4(5)$ \\
\hline$£ 151$ to $£ 200, n(\%)$ & $1(2)$ & $2(4)$ & $3(3)$ \\
\hline$£ 201$ to $£ 250, n(\%)$ & $9(21)$ & $6(13)$ & $15(17)$ \\
\hline$£ 251$ to $£ 300, n(\%)$ & $2(7)$ & $4(9)$ & $6(7)$ \\
\hline$£ 301$ to $£ 350, n(\%)$ & $7(16)$ & $9(20)$ & $16(18)$ \\
\hline$£ 351$ or above, n (\%) & $20(47)$ & $24(53)$ & $44(50)$ \\
\hline \multicolumn{4}{|l|}{ Housing tenure } \\
\hline Owned outright, n (\%) & $6(13)$ & $3(7)$ & $9(10)$ \\
\hline Shared ownership, n (\%) & $0(0)$ & $1(2)$ & $1(1)$ \\
\hline Mortgage/loan, n (\%) & $16(34)$ & $26(59)$ & $42(46)$ \\
\hline Privately rented, $\mathrm{n}(\%)$ & $10(21)$ & $5(11)$ & $15(16)$ \\
\hline Council rented, n (\%) & $8(17)$ & $4(9)$ & $12(13)$ \\
\hline Other social rented, n (\%) & $6(13)$ & $5(11)$ & $11(12)$ \\
\hline Other, n (\%) & $1(2)$ & $0(0)$ & $1(1)$ \\
\hline \multicolumn{4}{|l|}{ IMD deprivation quintile-based group } \\
\hline Most deprived, n (\%) & $8(17)$ & $7(16)$ & $15(16)$ \\
\hline 2nd group, n (\%) & $16(34)$ & $11(24)$ & $27(29)$ \\
\hline 3rd group, n (\%) & $10(21)$ & $15(33)$ & $25(27)$ \\
\hline 4th group, $\mathrm{n}(\%)$ & $9(19)$ & $10(22)$ & $19(21)$ \\
\hline Least deprived & $4(9)$ & $2(4)$ & $6(7)$ \\
\hline AMC concern score (index child) $d$, mean (SD) & $11.3(3.5)$ & $12.9(3.8)$ & $12.0(3.7)$ \\
\hline AMC impact score (index child) d, mean (SD) & $35.0(13.3)$ & $40.2(14.3)$ & $37.5(14.0)$ \\
\hline
\end{tabular}

a Sample size for intervention arm ranges from 36 to 47 .

b Sample size for control arm ranges from 32 to 45 .

c Total sample size ranges from 73 to 92 .

SD standard deviation, $n$ numerator, $N$ denominator (sample size)

\section{Outcomes}

Table 6 presents the mean differences between trial arms in outcomes at the first follow-up (post-intervention) and the second follow-up $(6$ months postintervention). At the first follow-up, an adjusted mean difference of 3.2 (95\% confidence interval -0.8 to 7.3 ) was found for the primary outcome WEMWBS wellbeing measure, but this difference diminished by the second follow-up (adjusted mean difference - 0.7 (95\% confidence interval -5.3 to 3.9 ).

Twenty participants $(21.7 \%)$ reported thoughts of selfharm or suicidal ideation on question 9 of the PHQ-9 at least once during the study (15 participants reported once; 5 participants reported twice). Of the 25 reports, 13 were at baseline, 3 at the first follow-up, and 9 at the second follow-up.

Correlations between baseline and follow-up scores on continuous outcomes were generally moderate (Table 7 ). Estimated standard deviations for the study outcomes are presented by trial arm status in Table 8 .

\section{Feasibility of cost-effectiveness framework} Intervention resource use and costs

The resources required for the delivery of the programme were identified and measured, and unit costs obtained for all elements of resource use. These are detailed in Additional file 2.

\section{Resource use questionnaire}

A bespoke resource use questionnaire was developed in collaboration with parent carers. This involved two faceto-face meetings and further input and feedback via email and telephone. The designed measure comprised the core items for a standardized resource use measure [46], in addition to questions pertaining to other NHS, Social Services, and Local Authority support. Items were also included in relation to 'Support from others', 'Own expenses', 'Services/resources for your child', and 'Other services/resources used or things done in the last 6 months that improved your health/wellbeing'. Responses 
Table 4 Baseline scores on outcome measures by trial arm status

\begin{tabular}{|c|c|c|c|}
\hline Characteristic & Intervention $(N=47)^{a}$ & Control $(N=45)^{b}$ & All $(N=92)^{\circ}$ \\
\hline WEMWEBS wellbeing score, mean (SD) & $40.2(7.7)$ & $38.1(5.8)$ & $39.2(6.9)$ \\
\hline PHQ-9 depression scale score, mean (SD) & $10.2(5.7)$ & $11.5(4.9)$ & $10.9(5.3)$ \\
\hline At least moderate depression (PHQ-9 score $\geq 10$ ) & $18(42)$ & $30(67)$ & $48(55)$ \\
\hline \multicolumn{4}{|l|}{ Parent assessment of protective factors } \\
\hline Total score, mean (SD) & $3.8(0.6)$ & $3.5(0.5)$ & $3.7(0.5)$ \\
\hline Parental resilience, mean (SD) & $3.8(0.7)$ & $3.7(0.6)$ & $3.7(0.6)$ \\
\hline Social connections, mean (SD) & $3.7(0.9)$ & $3.1(1.0)$ & $3.4(1.0)$ \\
\hline Concrete support, mean (SD) & $3.8(0.7)$ & $3.6(0.7)$ & $3.7(0.7)$ \\
\hline Social/emotional competence, mean (SD) & $4.0(0.6)$ & $3.9(0.6)$ & $3.9(0.6)$ \\
\hline Health-promoting activities, mean (SD) & $25.0(9.6)$ & $25.8(8.2)$ & $25.4(8.9)$ \\
\hline Patient activation measure, mean (SD) & $53.7(12.1)$ & $53.9(10.8)$ & $53.8(11.4)$ \\
\hline \multicolumn{4}{|l|}{ EQ-5D-5L-mobility } \\
\hline No problems, n (\%) & $37(79)$ & $30(68)$ & $67(74)$ \\
\hline Slight problems, n (\%) & $2(4)$ & $13(30)$ & $15(16)$ \\
\hline Moderate problems, n (\%) & $5(11)$ & $1(2)$ & $6(7)$ \\
\hline Severe problems, n (\%) & $2(4)$ & $0(0)$ & $2(2)$ \\
\hline Extreme problems, n (\%) & $1(2)$ & $0(0)$ & $1(1)$ \\
\hline \multicolumn{4}{|l|}{ EQ-5D-5L_self-care } \\
\hline No problems, n (\%) & $36(77)$ & $42(95)$ & $78(86)$ \\
\hline Slight problems, n (\%) & $7(15)$ & $2(5)$ & $9(10)$ \\
\hline Moderate problems, n (\%) & $4(9)$ & $0(0)$ & $4(4)$ \\
\hline Severe problems, n (\%) & $0(0)$ & $0(0)$ & $0(0)$ \\
\hline Extreme problems, n (\%) & $0(0)$ & $0(0)$ & $0(0)$ \\
\hline \multicolumn{4}{|l|}{ EQ-5D-5L-usual activities } \\
\hline No problems, n (\%) & $20(43)$ & $18(40)$ & $38(41)$ \\
\hline Slight problems, n (\%) & $18(38)$ & $16(36)$ & $34(37)$ \\
\hline Moderate problems, n (\%) & $4(9)$ & $10(22)$ & $14(15)$ \\
\hline Severe problems, n (\%) & $3(6)$ & $1(2)$ & $4(4)$ \\
\hline Extreme problems, n (\%) & $2(4)$ & $0(0)$ & $2(2)$ \\
\hline \multicolumn{4}{|l|}{ EQ-5D-5L_pain/discomfort } \\
\hline No problems, n (\%) & $14(30)$ & $14(31)$ & $28(31)$ \\
\hline Slight problems, n (\%) & $17(37)$ & $23(51)$ & $40(44)$ \\
\hline Moderate problems, n (\%) & $11(24)$ & $6(13)$ & $17(19)$ \\
\hline Severe problems, n (\%) & $3(7)$ & $2(4)$ & $5(5)$ \\
\hline Extreme problems, n (\%) & $1(2)$ & $0(0)$ & $1(1)$ \\
\hline \multicolumn{4}{|l|}{ EQ-5D-5L-anxiety/depression } \\
\hline No problems, n (\%) & $7(15)$ & $6(14)$ & $13(14)$ \\
\hline Slight problems, n (\%) & $18(39)$ & $19(43)$ & $37(41)$ \\
\hline Moderate problems, n (\%) & $14(30)$ & $15(34)$ & $29(32)$ \\
\hline Severe problems, n (\%) & $5(11)$ & $4(9)$ & $9(10)$ \\
\hline Extreme problems, n (\%) & $2(4)$ & $0(0)$ & $2(2)$ \\
\hline EQ-5D-5L_visual analogue scale, mean (SD) & $58.9(22.4)$ & $56.3(22.5)$ & $57.7(22.3)$ \\
\hline EQ-5D-5L-health state utility value, mean (SD) & $0.670(0.244)$ & $0.723(0.203)$ & $0.696(0.225)$ \\
\hline
\end{tabular}


Table 4 Baseline scores on outcome measures by trial arm status (Continued)

\begin{tabular}{|c|c|c|c|}
\hline Characteristic & Intervention $(N=47)^{a}$ & Control $(N=45)^{b}$ & All $(N=92)^{c}$ \\
\hline Most negative category, n (\%) & $5(11)$ & $5(11)$ & $10(11)$ \\
\hline 2nd category, n (\%) & $21(45)$ & $25(56)$ & $46(50)$ \\
\hline 3rd category, n (\%) & $19(40)$ & $15(33)$ & $34(37)$ \\
\hline Most positive category, n (\%) & $2(4)$ & $0(0)$ & $2(2)$ \\
\hline \multicolumn{4}{|c|}{ ICECAP-A-love, friendship and support } \\
\hline Most negative category, n (\%) & $2(4)$ & $0(0)$ & $2(2)$ \\
\hline 2nd category, n (\%) & $17(37)$ & $21(48)$ & $38(42)$ \\
\hline 3rd category, n (\%) & $21(46)$ & $19(43)$ & $40(44)$ \\
\hline Most positive category, n (\%) & $6(13)$ & $4(9)$ & $10(11)$ \\
\hline \multicolumn{4}{|l|}{ ICECAP-A—being independent } \\
\hline Most negative category, n (\%) & $0(0)$ & $0(0)$ & $0(0)$ \\
\hline 2nd category, n (\%) & $4(9)$ & $8(18)$ & $12(14)$ \\
\hline 3rd category, n (\%) & $27(61)$ & $21(48)$ & $48(55)$ \\
\hline Most positive category, n (\%) & $13(30)$ & $15(34)$ & $28(32)$ \\
\hline \multicolumn{4}{|c|}{ ICECAP-A—achievement and progress } \\
\hline Most negative category, n (\%) & $2(4)$ & $2(5)$ & $4(4)$ \\
\hline 2nd category, n (\%) & $23(51)$ & $22(50)$ & $45(51)$ \\
\hline 3rd category, n (\%) & $19(42)$ & $17(39)$ & $36(40)$ \\
\hline Most positive category, n (\%) & $1(2)$ & $3(7)$ & $4(4)$ \\
\hline \multicolumn{4}{|l|}{ ICECAP-A—enjoyment and pleasure } \\
\hline Most negative category, n (\%) & $1(2)$ & $0(0)$ & $1(1)$ \\
\hline 2nd category, n (\%) & $26(58)$ & $32(73)$ & $58(65)$ \\
\hline 3rd category, n (\%) & $18(40)$ & $12(27)$ & $30(34)$ \\
\hline Most positive category, n (\%) & $0(0)$ & $0(0)$ & $0(0)$ \\
\hline ICECAP-A—tariff, mean (SD) & $0.674(0.157)$ & $0.637(0.154)$ & $0.655(0.156)$ \\
\hline
\end{tabular}

a Sample size for intervention arm ranges from 36 to 47

${ }^{b}$ Sample size for control arm ranges from 32 to 45

' Total sample size ranges from 73 to 92

d "Index child" is the first child for whom the parent reported data at baseline

$S D$ standard deviation, $n$ numerator, $N$ denominator (sample size)

to the questionnaire at 6 months post-intervention by trial arm are provided in Additional file 3.

\section{QALY and WALY measures}

Table 9 presents the EQ-5D-5L QALYs and ICECAP-A WALYs by trial arm. These figures indicate the completeness of the data at each of the baseline and followup points.

\section{Feasibility of delivery}

According to facilitators' self-report checklists, $90 \%$ of activities were delivered across all groups. Scores from researcher checklists of the nine recorded modules similarly indicated that $91 \%$ of activities were delivered. The activities that were not delivered only included some icebreakers and concluding activities, not the main programme content. The two researchers were in agreement for $98 \%$ of assessed activities (only disagreeing in one concluding activity), showing high reliability of using the checklists to assess the content delivered.

\section{Group session attendance}

Sixteen (34\%) participants allocated to the intervention arm did not attend any group intervention sessions. Twenty-seven of the 47 (57\%, 95\% confidence interval: $42 \%$ to $72 \%$ ) participants in the intervention arm attended at least two-thirds of the sessions. The minimum number of participants attending any sessions was two, which occurred in six sessions across four groups.

There was no clear evidence of a relationship between attendance and baseline scores on outcome measures. Four of the participants who did not attend any sessions and were interviewed reported practical reasons for nonattendance, such as the distance to travel to sessions, child health, parent health, childcare, or work commitments. Twenty-two (47\%) intervention arm participants 
Table 5 Example quotes from participant interviews about acceptability of trial processes

\begin{tabular}{|c|}
\hline $\begin{array}{l}\text { nline, but maybe a slight conversation with some parent } \\
\text { 'hich would be better for you?' then maybe a choice } \\
\text { eing too random might be better. [Intervention } \\
\text { asures } \\
\text { ind doing questionnaires anyway, depending on how it's } \\
\text { y weren't onerous questionnaires, they were alright... I } \\
\text { nd was pleased with the vouchers. } \\
\text { actually, I thought they were good. It was just nice to } \\
\text { ght questions for once. } \\
\text { emotional at the beginning and I must admit, I would } \\
\text { to have done it on my own because I got really choked } \\
\text { ) It was at a time when I was really struggling } \\
\text { eally didn't want to be observed. (...) The end } \\
\text { felt slightly nervous because I didn't remember what I } \\
\text { one I thought I really want this to be a success because }\end{array}$ \\
\hline
\end{tabular}

also missed one or more sessions. The reasons provided for missing sessions were most commonly work commitments and parent or child health; frequencies are presented in Table 10.

\section{Engagement with online resources}

Participants reported their use of the online resources at first and second follow-up. A pattern emerged in which participants in the intervention arm were less likely to use the resources,and used fewer of them, compared to those in the control arm (Table 11).

\section{Discussion}

This study has demonstrated that it was feasible to set up and deliver the HPC programme in the community and the trial design and cost-effectiveness framework appeared generally feasible and acceptable to participants. Six venues were established for group delivery in a variety of community settings and in city and rural locations in Cornwall, Devon, and Somerset. Two Lead Facilitators, six Assistant Facilitators, and three reserve facilitators were recruited and trained to deliver the programme. According to facilitators' self-reports and a sample of researcher-coded session recordings, the group-based programme was delivered as designed across all groups.

There was considerable interest in the study from parent carers, indicating that a similar recruitment strategy could be effective for recruiting participants to sites in a definitive trial. Social media and events were found to be the most helpful elements of the recruitment strategy and should be utilised in any subsequent evaluation or implementation. A sufficient number of participants were recruited in each study site and randomised to form viable groups in the intervention $\operatorname{arm}(n=92)$.

Attrition of participants from the trial was low, with outcome data collected from 91\% (95\% confidence interval $84 \%$ to $96 \%$ ) of participants at postintervention and 90\% (95\% confidence interval 82\% to $95 \%$ ) of participants at 6-month follow-up. This was above the study target of $80 \%$ and was achieved utilising a combination of automated email reminders, phone calls, text messages and vouchers as acknowledgements. This system should be replicated in a definitive trial to promote similar follow-up rates. However, given the findings in a review of attrition in external pilot trials, which found a large amount of variability in the difference in attrition rates between pilot trials and their associated full trials, any estimate of likely follow-up should still be cautious [47].

In addition, the number of participants that provided completed questionnaires with no missing data on outcome measures ranged from 74 (80\%) to 83 (90\%) at post-intervention and from $71(77 \%)$ to 78 (85\%) at 6-month follow-up. Generally, across all measures, the earlier items were more likely to be completed than the later items. On inspection of the data and electronic patient-reported outcomes system, it appears that this may have been in part due to the layout and need for scrolling to later items on some devices. The formatting and presentation of the measures on all types of devices should be reviewed in a subsequent study to prevent this. The length and number of questionnaires should also be considered as fatigue may have been a factor.

The trial design was generally acceptable to parent carers, although many would have preferred to choose their way of accessing the programme rather than undergo random allocation. A partially randomised patient preference trial could be considered to 
Table 6 Comparison of outcomes between trial arms

\begin{tabular}{|c|c|c|c|c|c|c|c|}
\hline \multirow[t]{2}{*}{ Outcome } & \multicolumn{2}{|c|}{ Intervention (I) } & \multicolumn{2}{|c|}{ Control (C) } & \multirow{2}{*}{$\begin{array}{l}\text { Mean Difference } \\
\text { Crude }(I-C)\end{array}$} & \multicolumn{2}{|c|}{ Adjusted mean difference } \\
\hline & $\mathrm{N}$ & mean (SD) & $\mathrm{N}$ & mean (SD) & & estimate & $95 \% \mathrm{Cl}$ \\
\hline \multicolumn{8}{|l|}{ First follow-up } \\
\hline WEMWEBS wellbeing score & 44 & $46.4(7.0)$ & 34 & $43.4(6.3)$ & 3.1 & 3.2 & -0.8 to 7.3 \\
\hline PHQ-9 depression scale score & 42 & $7.8(4.4)$ & 35 & $8.8(4.8)$ & -1.0 & -0.9 & -3.7 to 1.9 \\
\hline \multicolumn{8}{|c|}{ Parent assessment of protective factors } \\
\hline Total score & 42 & $4.0(0.5)$ & 32 & $3.8(0.5)$ & 0.1 & 0.1 & -0.2 to 0.5 \\
\hline Parental resilience & 45 & $4.1(0.6)$ & 35 & $3.9(0.5)$ & 0.2 & 0.2 & -0.2 to 0.5 \\
\hline Social connections & 43 & $3.7(1.0)$ & 33 & $3.6(1.0)$ & 0.1 & 0.1 & -0.5 to 0.8 \\
\hline Concrete support & 44 & $3.9(0.6)$ & 34 & $3.8(0.6)$ & 0.1 & 0.1 & -0.3 to 0.5 \\
\hline Social/emotional competence & 44 & $4.2(0.5)$ & 33 & $4.0(0.6)$ & 0.2 & 0.2 & -0.2 to 0.5 \\
\hline Health-promoting activities & 44 & $30.6(8.7)$ & 35 & $28.6(7.7)$ & 2.0 & 2.0 & -3.9 to 8.0 \\
\hline Patient activation measure & 43 & $59.1(13.2)$ & 34 & $57.6(10.1)$ & 1.4 & 1.4 & -5.8 to 8.7 \\
\hline \multicolumn{8}{|l|}{ Second follow-up } \\
\hline WEMWEBS wellbeing score & 43 & $44.4(8.3)$ & 35 & $44.9(6.7)$ & -0.5 & -0.7 & -5.3 to 3.9 \\
\hline PHQ-9 depression scale score & 42 & $9.1(6.4)$ & 31 & $8.5(4.4)$ & 0.8 & 0.9 & -3.1 to 4.8 \\
\hline \multicolumn{8}{|c|}{ Parent assessment of protective factors } \\
\hline Total score & 40 & $4.0(0.5)$ & 32 & $3.8(0.5)$ & 0.1 & 0.1 & -0.2 to 0.4 \\
\hline Parental resilience & 45 & $4.0(0.5)$ & 36 & $4.0(0.5)$ & 0.006 & 0.002 & -0.3 to 0.3 \\
\hline Social connections & 43 & $3.6(1.0)$ & 34 & $3.5(1.1)$ & 0.1 & 0.1 & -0.5 to 0.7 \\
\hline Concrete support & 45 & $4.0(0.7)$ & 36 & $3.8(0.7)$ & 0.2 & 0.2 & -0.2 to 0.6 \\
\hline Social/emotional competence & 43 & $4.2(0.5)$ & 35 & $4.0(0.6)$ & 0.1 & 0.1 & -0.3 to 0.5 \\
\hline Health-promoting activities & 42 & $29.5(9.7)$ & 34 & $30.5(9.8)$ & -1.2 & -1.1 & -10.9 to 8.7 \\
\hline Patient activation measure & 44 & $59.1(15.2)$ & 34 & $61.7(12.7)$ & -2.7 & -2.7 & -11.1 to 5.8 \\
\hline
\end{tabular}

$S D$ standard deviation, $\mathrm{Cl}$ confidence interval, $N$ denominator (sample size)

increase participation in a future trial [48]. The type of control used in future could also be considered and discussed with patient and public involvement group members to see if there might be a more acceptable option, such as a possible waitlist control. The outcome measures were largely acceptable to participants, although some technical problems with the electronic patient-reported outcomes system were reported. The electronic patient-reported outcomes system should be revisited and tested by users before implementation in the definitive trial.

The identification of resources required to deliver the intervention and their associated costs will be used to plan and budget for future implementation, including for a definitive trial. As the programme is refined and implementation by community organisations is planned, the cost implications of any changes will be explored. The cost of implementing the

Table 7 Pearson correlation ( $r$ ) between baseline score and follow-up score for each outcome

\begin{tabular}{|c|c|c|c|c|}
\hline \multirow[t]{2}{*}{ Outcome } & \multicolumn{2}{|c|}{ First follow-up } & \multicolumn{2}{|c|}{ Second follow-up } \\
\hline & Number & r $(95 \% \mathrm{Cl})$ & Number & r $(95 \% \mathrm{Cl})$ \\
\hline WEMWEBS wellbeing & 74 & 0.57 (0.39 to 0.71$)$ & 76 & 0.40 (0.19 to 0.57$)$ \\
\hline PHQ-9 depression & 73 & 0.49 (0.29 to 0.65$)$ & 70 & 0.65 (0.48 to 0.76$)$ \\
\hline Parent assessment of protective factors ${ }^{a}$ & 61 & 0.78 (0.66 to 0.87$)$ & 62 & 0.68 (0.52 to 0.79$)$ \\
\hline Health-promoting activities & 76 & 0.46 (0.26 to 0.62$)$ & 73 & 0.45 (0.25 to 0.62$)$ \\
\hline Parent activation measure & 74 & 0.54 (0.35 to 0.68$)$ & 75 & 0.62 (0.46 to 0.74$)$ \\
\hline
\end{tabular}

a Parent assessment of protective factors

$r$ Pearson correlation coefficient, $\mathrm{Cl}$ confidence interval, $\mathrm{N}$ denominator (sample size) 
Table 8 Estimated standard deviations (SDs) for study outcomes by trial arm status

\begin{tabular}{|c|c|c|c|c|c|c|}
\hline \multirow[t]{2}{*}{ Outcome } & \multicolumn{2}{|c|}{ Intervention } & \multicolumn{2}{|c|}{ Control } & \multicolumn{2}{|l|}{ All } \\
\hline & $\mathbf{N}$ & SD $(95 \% \mathrm{Cl})$ & $\mathbf{N}$ & SD $(95 \% \mathrm{Cl})$ & $\mathrm{N}$ & SD $(95 \% \mathrm{Cl})$ \\
\hline \multicolumn{7}{|l|}{ Baseline } \\
\hline WEMWEBS wellbeing & & & & & 87 & $6.9(6.0$ to 8.1$)$ \\
\hline PHQ-9 depression & & & & & 88 & 5.3 (4.6 to 6.2$)$ \\
\hline Parent assessment of protective factors ${ }^{a}$ & & & & & 78 & 0.54 (0.46 to 0.64$)$ \\
\hline Health-promoting activities & & & & & 88 & $8.9(7.7$ to 10.4$)$ \\
\hline Parent activation measure & & & & & 88 & $11.4(9.9$ to 13.4$)$ \\
\hline \multicolumn{7}{|l|}{ First follow-up } \\
\hline WEMWEBS wellbeing & 44 & $7.0(5.8$ to 8.9$)$ & 34 & $6.3(5.1$ to 8.3$)$ & 78 & $6.8(5.9$ to 8.1$)$ \\
\hline PHQ-9 depression & 42 & 4.4 (3.6 to 5.6$)$ & 35 & 4.8 (3.8 to 6.2$)$ & 77 & 4.6 (3.9 to 5.4$)$ \\
\hline Parent assessment of protective factors ${ }^{a}$ & 42 & 0.53 (0.44 to 0.68$)$ & 32 & 0.45 (0.36 to 0.60$)$ & 74 & 0.50 (0.43 to 0.60$)$ \\
\hline Health-promoting activities & 44 & $8.7(7.2$ to 11.1$)$ & 35 & $7.7(6.2$ to 10.1$)$ & 79 & 8.3 (7.2 to 9.8$)$ \\
\hline Parent activation measure & 43 & $13.2(10.9$ to 16.8$)$ & 34 & $10.1(8.1$ to 13.3$)$ & 77 & $11.9(10.3$ to 14.1$)$ \\
\hline \multicolumn{7}{|l|}{ Second follow-up } \\
\hline WEMWEBS wellbeing & 43 & 8.3 (6.8 to 10.5$)$ & 35 & 6.7 (5.4 to 8.7$)$ & 78 & 7.5 (6.5 to 9.0$)$ \\
\hline PHQ depression & 42 & $6.4(5.2$ to 8.1$)$ & 31 & 4.4 (3.5 to 5.9$)$ & 73 & 5.6 (4.8 to 6.7$)$ \\
\hline Parent assessment of protective factors ${ }^{a}$ & 40 & 0.54 (0.44 to 0.69$)$ & 32 & 0.48 (0.38 to 0.63$)$ & 72 & 0.51 (0.44 to 0.61$)$ \\
\hline Health-promoting activities & 42 & 9.7 (8.0 to 12.3$)$ & 34 & 9.8 (7.9 to 12.9$)$ & 76 & 9.7 (8.3 to 11.5$)$ \\
\hline Parent activation measure & 44 & $15.2(12.6$ to 19.3$)$ & 34 & $12.7(10.2$ to 16.7$)$ & 78 & $14.2(12.2$ to 16.8$)$ \\
\hline
\end{tabular}

${ }^{a}$ Total score on Parent assessment of protective factors

$S D$ standard deviation, $\mathrm{Cl}$ confidence interval, $N$ denominator (sample size)

programme is highly likely to reduce over time as facilitators are trained to deliver repeated groups and certain materials can be reused.

The number recruited to take part represented only $50 \%$ of those who initially enquired, and the most common reasons for not taking part were practical barriers to attending groups. Among those taking part, attendance at group sessions was variable and often lower than intended. Further exploration of ways to reduce barriers to access and participation, which may include reducing the time from recruitment to randomisation and the feasibility of offering

Table 9 EQ-5D-5L quality-adjusted life-years (QALYS) and ICECAP-A wellbeing-adjusted life years (WALYS), by trial arm

\begin{tabular}{|c|c|c|c|c|c|c|c|}
\hline \multirow[t]{2}{*}{ Measure: time point } & \multicolumn{2}{|c|}{ Intervention (I) } & \multicolumn{2}{|c|}{ Control (C) } & \multirow{2}{*}{$\begin{array}{l}\text { Mean difference } \\
\text { (I-C) (unadjusted) }\end{array}$} & \multicolumn{2}{|c|}{ Adjusted mean difference* } \\
\hline & $\bar{N}$ & $\overline{\text { mean }(\mathrm{SD}) \text { [range] }}$ & $\bar{N}$ & $\begin{array}{l}\text { mean (SD) } \\
\text { [range] }\end{array}$ & & estimate & $95 \% \mathrm{Cl}$ \\
\hline EQ-5D-5L: baseline & 44 & $\begin{array}{l}0.670(0.244) \\
{[-0.098 \text { to } 1]}\end{array}$ & 44 & $\begin{array}{l}0.723(0.203) \\
{[-0.239 \text { to } 1]}\end{array}$ & & & \\
\hline EQ-5D: 14 weeks & 45 & $\begin{array}{l}0.659(0.269) \\
{[-0.225 \text { to } 1]}\end{array}$ & 38 & $\begin{array}{l}0.742(0.166) \\
{[0.238 \text { to } 1]}\end{array}$ & -0.083 & -0.099 & -0.203 to 0.006 \\
\hline EQ-5D: 9.5 months & 40 & $\begin{array}{l}0.645(0.228) \\
{[-0.032 \text { to } 1]}\end{array}$ & 31 & $\begin{array}{l}0.675(0.185) \\
{[0.364 \text { to } 1]}\end{array}$ & -0.030 & -0.029 & -0.130 to 0.072 \\
\hline EQ-5D QALYs: 9.5 months & 35 & $\begin{array}{l}0.488(0.117) \\
{[0.195 \text { to } 0.644]}\end{array}$ & 26 & $\begin{array}{l}0.519(0.090) \\
{[0.301 \text { to } 0.663]}\end{array}$ & -0.031 & -0.024 & -0.079 to 0.030 \\
\hline ICECAP-A: baseline & 44 & $\begin{array}{l}0.674(0.157) \\
{[0.291 \text { to } 0.920]}\end{array}$ & 44 & $\begin{array}{l}0.637(0.154) \\
{[0.269 \text { to } 0.942]}\end{array}$ & & & \\
\hline ICECAP-A: 14 weeks & 45 & $\begin{array}{l}0.719(0.169) \\
{[0.363 \text { to } 0.969]}\end{array}$ & 34 & $\begin{array}{l}0.718(0.138) \\
{[0.371 \text { to } 0.934]}\end{array}$ & 0.001 & -0.013 & -0.072 to 0.047 \\
\hline ICECAP-A: 9.5 months & 44 & $\begin{array}{l}0.713(0.189) \\
{[0.251 \text { to } 1]}\end{array}$ & 33 & $\begin{array}{l}0.707(0.159) \\
{[0.432 \text { to } 1]}\end{array}$ & 0.006 & 0 & -0.072 to 0.072 \\
\hline ICECAP-A WALYs: 9.5 months & 40 & $\begin{array}{l}0.512(0.108) \\
{[0.239 \text { to } 0.663]}\end{array}$ & 27 & $\begin{array}{l}0.519(0.083) \\
{[0.341 \text { to } 0.699]}\end{array}$ & -0.007 & -0.007 & -0.044 to 0.029 \\
\hline
\end{tabular}


Table 10 Reasons for missed sessions

\begin{tabular}{ll}
\hline Reason & Number (\%) \\
\hline Work & $13(18 \%)$ \\
Parent unwell & $12(16 \%)$ \\
Child unwell & $11(15 \%)$ \\
Unknown & $8(11 \%)$ \\
Other commitment & $7(10 \%)$ \\
Parent health appointment & $5(7 \%)$ \\
Child health appointment & $5(7 \%)$ \\
No further contact & $5(7 \%)$ \\
Childcare & $2(3 \%)$ \\
Bereavement & $1(1 \%)$ \\
Other family member unwell & $1(1 \%)$ \\
Missed communication & $1(1 \%)$ \\
Forgot session was running & $1(1 \%)$ \\
Job interview & $1(1 \%)$ \\
Total & 73
\end{tabular}

further support, such as providing funded childcare, is needed. Larger minimum group sizes at the outset would help to ensure that the attendance is sufficient to enable the programme to be delivered with fidelity to function (see findings from the process evaluation reported separately (Lloyd J, Bjornstad G, Borek A, Cuffe-Fuller B, Fredlund M, McDonald A, Tarrant M, Berry V, Wilkinson K, Mitchell S, et al: The Healthy Parent Carers programme: mixed-methods process evaluation and refinement of a health promotion intervention, Under review)).

This study provides important information about parameters that will be used for calculating the sample size for the definitive trial, including the variation in group sizes for intervention delivery, the follow-up percentage and the standard deviation of the putative primary outcome (the WEMWBS).

This study was not conducted in an ethnically diverse part of the UK and as such does not provide information about the relevance and acceptability of the programme

Table 11 Self-reported use of online material in the intervention arm

\begin{tabular}{llllll}
\hline Amount & \multicolumn{2}{l}{ By first follow-up } & & \multicolumn{2}{l}{ By second follow-up } \\
\cline { 2 - 3 } & Intervention & Control & & Intervention & Control \\
& $\mathbf{N = 4 7}$ & $\mathbf{N = 4 5}$ & & $\mathbf{N = 4 7}$ & $\mathbf{N = 4 5}$ \\
\hline None, n (\%) & $20(43 \%)$ & $4(9 \%)$ & $27(57 \%)$ & $10(22 \%)$ \\
$25 \%, \mathrm{n}(\%)$ & $13(28 \%)$ & $1(2 \%)$ & $11(23 \%)$ & $8(18 \%)$ \\
$50 \%, \mathrm{n}(\%)$ & $3(6 \%)$ & $3(7 \%)$ & $5(11 \%)$ & $7(16 \%)$ \\
More than 50\%, n (\%) & $8(17 \%)$ & $20(44 \%)$ & $2(4 \%)$ & $12(27 \%)$ \\
Missing, n (\%) & $3(6 \%)$ & $17(38 \%)$ & $2(4 \%)$ & $8(18 \%)$ \\
\hline
\end{tabular}

$n$ numerator, $N$ denominator (sample size) to parent carers from a range of ethnical and cultural backgrounds, nor did we seek to establish the feasibility of delivering group sessions with interpreters for those who cannot communicate in English. Most work on ethnicity and parenting interventions has been conducted in the USA and is equivocal about whether outcomes differ by ethnicity $[49,50]$. Understanding how ethnicity might influence the development of a shared group identity, recognised as a key mechanism of action for groupbased programmes, will be explored in future work.

Given the current context of the Covid-19 pandemic and need for social distancing, delivering in-person groups is not possible and will likely be affected in the near future. Therefore, we will explore virtual groups using online videoconferencing as an alternative mode of delivery.

\section{Conclusions}

The study demonstrated that it was feasible to train facilitators and deliver the peer-led, group-based programme in community settings. The number of parent carers who expressed interest signifies the need for such a programme and the feasibility of recruiting to a definitive trial. Loss to follow-up was low. However, many interested parents were unable to take part and attendance was variable. Further research is needed to explore ways to reduce barriers to participation in person. Research assessing the feasibility and acceptability of programme content and delivery for more ethnically diverse groups, and potentially using interpreters is also needed to increase potential reach. Given the Covid-19 pandemic and delivery format feedback, there is also a need to investigate remote or blended delivery strategies. Although the results indicate that a definitive trial is feasible, programme impact would be strengthened through exploration of these uncertainties.

\section{Supplementary Information}

The online version contains supplementary material available at https://doi. org/10.1186/s40814-021-00881-5.

Additional file 1. CONSORT 2010 checklist.

Additional file 2. Healthy Parent Carers Programme resource requirements and unit costs.

Additional file 3. Resource use at six months post-HPC intervention, by trial group.

\footnotetext{
Acknowledgements

We thank members of the PenCRU Family Faculty and the Stakeholders Advisory Group for their involvement in the development of the intervention and the design and execution of this study, and the Council for Disabled Children for their collaboration. The authors are grateful to all participating parent carers and their families and the facilitators who delivered the programme. We also acknowledge the support of the National Institute for Health Research Clinical Research Network (NIHR CRN).
} 


\section{Authors' contributions}

All authors contributed. CM led the development and preliminary evaluation of the programme and was the principal investigator of this study. GB managed the project, including overseeing day-to-day recruitment and data collection. $G B$ and $C M$ drafted the initial study design with input from $O U$, $A B, A H, V B, J L, M T, S R, M F, A M$, and $S L . A B, A M, M F$, and $C M$ designed the original programme. OU designed the quantitative analysis plan and analysed the baseline and outcome data. GB analysed the recruitment and attendance data. $A B, B C F, A G$, and $J L$ coded and analysed the qualitative data. AH designed the methods to develop and test a cost-effectiveness framework and analysed the resource use and costs data. AB, CM, VB, JL, MT, KW, and BCF designed the fidelity and process evaluation. KW recruited programme facilitators and arranged delivery sites. AM, MF, BCF, and KW planned, prepared, and delivered facilitator training and support. GB, BCF, KF, KW, and AG recruited participants and facilitated data collection. KF facilitated all public involvement. SR coordinated the CTU involvement in the design and conduct of the project and database management. SL facilitated infrastructure support through the National Institute for Health Research Applied Research Collaboration South West Peninsula. All authors served on the Trial Management Group, contributed to drafting this paper, and approved the final manuscript. The study sponsor is the University of Exeter.

\section{Funding}

This paper presents independent research funded by the National Institute for Health Research (NIHR) under its Research for Patient Benefit (RfPB) Programme (Grant Reference Number PB-PG-0317-20044). We also acknowledge support from the National Institute for Health Research Applied Research Collaboration South West Peninsula. The views and opinions expressed in this paper are those of the authors and not necessarily those of the NIHR or the Department of Health and Social Care. Delivery of the Healthy Parent Carers programme was funded by Public Health England, Kernow Clinical Commissioning Group, Northern, Eastern and Western Devon Clinical Commissioning Group, and a grant from the National Lottery Community Fund through the Reaching Communities programme. Peer review of the study design was provided during the NIHR funding application process. The funders have had no involvement in the execution of the trial, analyses, interpretation of the data, writing of the report, or the decision to submit the report for publication.

\section{Availability of data and materials}

The datasets analysed during the current study are available from the corresponding author on reasonable request via Open Research Exeter: https://doi.org/10.24378/exe.3423.

\section{Declarations}

\section{Ethics approval and consent to participate}

Ethics approval for the study was received on 20 August 2018 from the University of Exeter Medical School Research Ethics Committee in the College of Medicine and Health (UEMS REC 18/06/174). All participants in this study provided written consent to participate.

\section{Consent for publication}

Not applicable.

\section{Competing interests}

The authors declare that they have no competing interests.

\section{Author details}

'Peninsula Childhood Disability Research Unit (PenCRU), University of Exeter Medical School, University of Exeter, St. Luke's Campus, Heavitree Road, Exeter EX1 2LU, UK. ${ }^{2}$ NIHR Applied Research Collaboration South West Peninsula (PenARC), University of Exeter Medical School, University of Exeter, St. Luke's Campus, Heavitree Road, Exeter EX1 2LU, UK. ${ }^{3}$ Relational Health Group, Institute of Health Research, University of Exeter Medical School, University of Exeter, Exeter EX1 2LU, UK. ${ }^{4}$ Health Economics Group and NIHR Applied Research Collaboration (PenARC) South West Peninsula, University of Exeter Medical School, University of Exeter, Exeter EX1 2LU, UK. ${ }^{5}$ Nuffield Department of Primary Care Health Sciences, Medical Sciences Division, University of Oxford, Radcliffe Observatory Quarter, Woodstock Road, Oxford OX2 6GG, UK. ${ }^{6}$ Exeter Clinical Trials Unit, University of Exeter Medical School, University of Exeter, St. Luke's Campus, Heavitree Road, Exeter EX1 2LU, UK.
Received: 10 March 2021 Accepted: 2 July 2021

Published online: 23 July 2021

\section{References}

1. Department for Education: Special educational needs and disability: an analysis and summary of data sources. London; 2020.

2. Department for Work and Pensions: Family Resources Survey 2018/19. London; 2020

3. Barlow J, Cullen-Powell L, Cheshire A. Psychological well-being among mothers of children with cerebral palsy. Early Child Dev Care. 2006;176(3-4): 421-8. https://doi.org/10.1080/0300443042000313403.

4. Brehaut JC, Kohen DE, Raina P, Walter SD, Russell DJ, Swinton M, et al. The health of primary caregivers of children with cerebral palsy: how does it compare with that of other Canadian caregivers? Pediatrics. 2004;114(2): e182-91. https://doi.org/10.1542/peds.114.2.e182.

5. Brehaut JC, Kohen DE, Garner RE, Miller AR, Lach LM, Klassen AF, et al. Health among caregivers of children with health problems: findings from a Canadian population-based study. Am J Public Health. 2009;99(7):1254-62. https://doi.org/10.2105/AJPH.2007.129817.

6. Emerson E. Mothers of children and adolescents with intellectual disability: social and economic situation, mental health status, and the self-assessed social and psychological impact of the child's difficulties. J Intellect Disabil Res. 2003;47(4-5):385-99. https://doi.org/10.1046/j.1365-2788.2003.00498.x.

7. Gallagher S, Phillips AC, Oliver C, Carroll D. Predictors of psychological morbidity in parents of children with intellectual disabilities. J Pediatr Psychol. 2008;33(10):1129-36. https://doi.org/10.1093/jpepsy/jsn040.

8. Lach LM, Kohen DE, Garner RE, Brehaut JC, Miller AR, Klassen AF, et al. The health and psychosocial functioning of caregivers of children with neurodevelopmental disorders. Disabil Rehabil. 2009;31(9):741-52. https:// doi.org/10.1080/08916930802354948.

9. Murphy NA, Christian B, Caplin DA, Young PC. The health of caregivers for children with disabilities: caregiver perspectives. Child Care Health Dev. 2007;33(2):180-7.

10. Oelofsen N, Richardson P. Sense of coherence and parenting stress in mothers and fathers of preschool children with developmental disability. J Intellect Dev Disabil. 2006;31(1):1-12. https://doi.org/10.1080/13668250500349367.

11. Olsson MB, Hwang C. Depression in mothers and fathers of children with intellectual disability. J Intellect Disabil Res. 2001;45(6):535-43. https://doi. org/10.1046/j.1365-2788.2001.00372.x.

12. Singer GH, Floyd F. Meta-analysis of comparative studies of depression in mothers of children with and without developmental disabilities. Am J Ment Retard. 2006;111(3):155-69. https://doi.org/10.1352/0895-8017(2 006)111[155:MOCSOD]2.0.CO;2.

13. Tong HC, Haig AJ, Nelson VS, Yamakawa KS-J, Kandala G, Shin KY. Low back pain in adult female caregivers of children with physical disabilities. Arch Pediatr Adolesc Med. 2003;157(11):1128-33. https://doi.org/10.1001/a rchpedi.157.11.1128.

14. Lee M, Park C, Matthews AK, Hsieh K. Differences in physical health, and health behaviors between family caregivers of children with and without disabilities. Disabil Health J. 2017;10(4):565-70. https://doi.org/10.1016/j. dhjo.2017.03.007.

15. Arim RG, Miller AR, Kohen DE, Guèvremont A, Lach LM, Brehaut JC. Changes in the health of mothers of children with neurodevelopmental disabilities: an administrative data study. Res Dev Disabil. 2019;86:76-86. https://doi. org/10.1016/j.ridd.2018.12.007.

16. Masulani-Mwale C, Mathanga D, Silungwe D, Kauye F, Gladstone M. Parenting children with intellectual disabilities in Malawi: the impact that reaches beyond coping? Child Care Health Dev. 2016;42(6):871-80.

17. Gona JK, Mung'ala-Odera V, Newton CR, Hartley S. Caring for children with disabilities in Kilifi, Kenya: what is the carer's experience? Child Care Health Dev. 2011;37(2):175-83.

18. Brehaut JC, Garner RE, Miller AR, Lach LM, Klassen AF, Rosenbaum PL, et al. Changes over time in the health of caregivers of children with health problems: growth-curve findings from a 10-year Canadian population-based study. Am J Public Health. 2011;101(12):2308-16. https://doi.org/10.2105/A JPH.2011.300298.

19. Resch JA, Mireles G, Benz MR, Grenwelge C, Peterson R, Zhang D. Giving parents a voice: a qualitative study of the challenges experienced by parents of children with disabilities. Rehabil Psychol. 2010;55(2):139-50. https://doi.org/10.1037/a0019473. 
20. Bartholomew Eldredge LK, Markham CM, Ruiter RA, Fernandez ME, Kok G, Parcel GS. Planning health promotion programs: an intervention mapping approach. 4th ed. San Francisco: Jossey-Bass; 2016.

21. Borek AJ, McDonald B, Fredlund M, Bjornstad G, Logan S, Morris C. Healthy Parent Carers programme: development and feasibility of a novel groupbased health-promotion intervention. BMC Public Health. 2018;18(1):270. https://doi.org/10.1186/s12889-018-5168-4.

22. Eldridge SM, Lancaster GA, Campbell MJ, Thabane L, Hopewell S, Coleman $\mathrm{CL}$, et al. Defining feasibility and pilot studies in preparation for randomised controlled trials: development of a conceptual framework. PLoS One. 2016; 11(3):e0150205.

23. Bjornstad G, Wilkinson K, Cuffe-Fuller B, Fitzpatrick K, Borek A, Ukoumunne $O C$, et al. Healthy Parent Carers peer-led group-based health promotion intervention for parent carers of disabled children: protocol for a feasibility study using a parallel group randomised controlled trial design. Pilot Feasibility Stud. 2019;5(1):1-13.

24. Tarrant M, Haslam C, Carter M, Calitri R, Haslam SA. Social identity interventions. In: Hagger MS, Cameron LD, Hamilton K, Lintunen T, editors. Handbook of Behavior Change. edn. New York: Cambridge University Press; 2020.

25. Hammond P. Staying alive: how to get the best out of the NHS - advice from a doctor. London: Quercus; 2015.

26. Aked J, Marks N, Cordon C, Thompson S. Five Ways to Wellbeing: a report presented to the Foresight Project on communicating the evidence base for improving people's well-being. London: Nef; 2009.

27. Tennant R, Hiller L, Fishwick R, Platt S, Joseph S, Weich S, et al. The WarwickEdinburgh mental well-being scale (WEMWBS): development and UK validation. Health Qual Outcomes. 2007;5(1):63. https://doi.org/10.1186/14 77-7525-5-63.

28. Kroenke K, Spitzer RL. The PHQ-9: a new depression diagnostic and severity measure. Psychiatr Ann. 2002;32(9):509-15. https://doi.org/10.3928/00485713-20020901-06

29. Kroenke K, Spitzer RL, Williams JB, Löwe B. The patient health questionnaire somatic, anxiety, and depressive symptom scales: a systematic review. Gen Hospital Psychiatry. 2010;32(4):345-59. https://doi.org/10.1016/j. genhosppsych.2010.03.006.

30. Wittkampf KA, Naeije L, Schene AH, Huyser J, van Weert HC. Diagnostic accuracy of the mood module of the Patient Health Questionnaire: a systematic review. Gen Hospital Psychiatry. 2007;29(5):388-95. https://doi. org/10.1016/j.genhosppsych.2007.06.004.

31. Bourke-Taylor H, Law M, Howie L, Pallant JF. Initial development of the Health Promoting Activities Scale to measure the leisure participation of mothers of children with disabilities. Am J Occup Ther. 2012;66(1):e1-e10. https://doi.org/10.5014/ajot.2012.000521.

32. Muskett $\mathrm{R}$, Bourke-Taylor $\mathrm{H}$, Hewitt $\mathrm{A}$. Intrarater reliability and other psychometrics of the Health Promoting Activities Scale (HPAS). Am J Occup Ther. 2017;71(4):1-8.

33. Hibbard JH, Mahoney ER, Stockard J, Tusler M. Development and testing of a short form of the patient activation measure. Health Serv Res. 2005; 40(6p1):1918-30.

34. Hibbard JH, Stockard J, Mahoney ER, Tusler M. Development of the Patient Activation Measure (PAM): conceptualizing and measuring activation in patients and consumers. Health Serv Res. 2004;39(4p1):1005-26.

35. Kiplinger VL, Browne CH. Parents' Assessment of Protective Factors: user's guide and technical report. Washington, DC: Center for the Study of Social Policy; 2014.

36. The EuroQol Group. EuroQol-a new facility for the measurement of healthrelated quality of life. Health Policy. 1990;16(3):199-208.

37. Al-Janabi H, Flynn TN, Coast J. Development of a self-report measure of capability wellbeing for adults: the ICECAP-A. Qual Life Res. 2012;21(1):16776. https://doi.org/10.1007/s11136-011-9927-2.

38. Al-Janabi H, Peters TJ, Brazier J, Bryan S, Flynn TN, Clemens S, et al. An investigation of the construct validity of the ICECAP-a capability measure. Qual Life Res. 2013;22(7):1831-40. https://doi.org/10.1007/s1113 6-012-0293-5.

39. Mitchell PM, Al-Janabi H, Byford S, Kuyken W, Richardson J, lezzi A, et al. Assessing the validity of the ICECAP-a capability measure for adults with depression. BMC Psychiatry. 2017;17(1):46. https://doi.org/10.1186/s12888-01 7-1211-8.

40. Ridyard CH, Hughes DA, D. Team. Development of a database of instruments for resource-use measurement: purpose, feasibility, and design. Value Health. 2012;15(5):650-5. https://doi.org/10.1016/j.jval.2012.03.004.
41. Herdman M, Gudex C, Lloyd A, Janssen M, Kind P, Parkin D, et al. Development and preliminary testing of the new five-level version of EQ-5D (EQ-5D-5L). Qual Life Res. 2011;20(10):1727-36. https://doi.org/10.1007/s11136-011-9903-X.

42. Flynn T, Huynh E, Peters T, Al-Janabi H, Clemens S, Moody A, et al. Scoring the Icecap-a capability instrument. Estimation of a UK General Population Tariff. Health Econ. 2015;24(3):258-69. https://doi.org/10.1002/hec.3014.

43. Satterthwaite FE. An approximate distribution of estimates of variance components. Biometrics Bull. 1946;2(6):110-4. https://doi.org/10.2307/3002019.

44. Eldridge SM, Chan CL, Campbell MJ, Bond CM, Hopewell S, Thabane L, et al. CONSORT 2010 statement: extension to randomised pilot and feasibility trials. Pilot Feasibility Stud. 2016;2(1):64. https://doi.org/10.1186/s40814-016-0105-8.

45. Department for Communities and Local Government. English indices of deprivation. 2015. https://www.gov.uk/government/statistics/english-indicesof-deprivation-2015. Accessed 12 May 2017.

46. Thorn JC, Brookes ST, Ridyard C, Riley R, Hughes DA, Wordsworth S, Noble SM, Thornton G, Hollingworth W. Core Items for a Standardized Resource Use Measure: Expert Delphi Consensus Survey. Value in Health. 2018;21(6): 640-9. https://doi.org/10.1016/j.jval.2017.06.011.

47. Cooper CL, Whitehead A, Pottrill E, Julious SA, Walters SJ. Are pilot trials useful for predicting randomisation and attrition rates in definitive studies: a review of publicly funded trials. Clin Trials. 2018;15(2):189-96. https://doi. org/10.1177/1740774517752113.

48. Wasmann KA, Wijsman P, van Dieren S, Bemelman W, Buskens C. Partially randomised patient preference trials as an alternative design to randomised controlled trials: systematic review and meta-analyses. BMJ Open. 2019; 9(10):e031151. https://doi.org/10.1136/bmjopen-2019-031151.

49. Reid M, Webster-Stratton C, Beauchaine T. Parent training in Head Start: a comparison of program response among African American, Asian American, Caucasian, and Hispanic mothers. Prev Sci. 2001;2(4):209-27. https://doi. org/10.1023/A:1013618309070.

50. Van Mourik K, Crone M, De Wolff M, Reis R. Parent training programs for ethnic minorities: a meta-analysis of adaptations and effect. Prev Sci. 2017; 18(1):95-105. https://doi.org/10.1007/s11121-016-0733-5.

\section{Publisher's Note}

Springer Nature remains neutral with regard to jurisdictional claims in published maps and institutional affiliations.

Ready to submit your research? Choose BMC and benefit from

- fast, convenient online submission

- thorough peer review by experienced researchers in your field

- rapid publication on acceptance

- support for research data, including large and complex data types

- gold Open Access which fosters wider collaboration and increased citations

- maximum visibility for your research: over $100 \mathrm{M}$ website views per year

At $\mathrm{BMC}$, research is always in progress.

Learn more biomedcentral.com/submissions 